\title{
"Doing What I can, but I got no Magic Wand:" A Snapshot of Early Childhood Educator Experiences and Efforts to Ensure Quality During the COVID-19 Pandemic
}

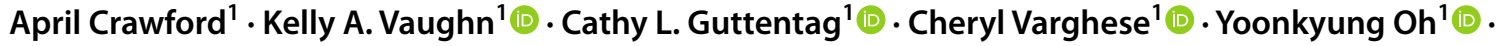 \\ Tricia A. Zucker ${ }^{1} \mathbb{D}$
}

Accepted: 17 May 2021 / Published online: 31 May 2021

(C) The Author(s), under exclusive licence to Springer Nature B.V. 2021

\begin{abstract}
The COVID-19 pandemic impacted early childhood programs serving infants, toddlers, and preschoolers in dramatic ways. After temporarily closing, many educators quickly adapted their procedures to ensure children's safety as they reopened to provide childcare for essential workers and then the community at large. This manuscript reports on statewide efforts to continue quality improvement initiatives for early childhood programs amidst the COVID-19 pandemic. We first describe the impacts of the COVID-19 pandemic for over 2000 educators - teachers, administrators, and specialists-who completed surveys in the Spring and Fall of 2020. These survey data come from a statewide system called the Texas Early Childhood Professional Development System (TECPDS), designed to track the professional development needs/progress of early childhood educators. Second, we describe an example of how a statewide professional development and quality improvement program shifted to remote delivery during the pandemic. As an increasing number of educators turn to virtual training resources, we explain lessons learned from these response efforts and how they can inform future virtual professional development efforts, even amidst crisis, to ensure that a focus on quality improvement continues while supporting teachers' individual needs.
\end{abstract}

Keywords Early childhood · Educators · Professional development $\cdot$ COVID-19 pandemic

\section{Introduction}

Millions of families in the U.S. rely on early childhood programs, including childcare centers, family childcare homes, Head Start, and public pre-kindergarten (Pre-K) programs, to enable parents to work. Prior to COVID-19, many of these programs were already operating on thin financial margins and struggled with high staff turnover and variable quality of care and instruction (e.g., Child Care Aware of America, 2019). When the pandemic hit in the spring of 2020 , the childcare industry was thrown into crisis as programs shut down, enrollment dropped, shortages of cleaning supplies hampered re-opening, and costs related to safety protocols and technology needs increased (U.S. Chamber

Kelly A. Vaughn

Kelly.A.Vaughn@uth.tmc.edu

1 Department of Pediatrics, McGovern Medical School, Children's Learning Institute, University of Texas Health Science Center at Houston, Houston, TX, USA of Commerce Foundation, 2020; Workman \& Jessen-Howard, 2020; Zero To Three, 2020). For example, in a survey published by NAEYC in July, 2020 of over 5000 childcare providers, $40 \%$ of respondents reported that they would close permanently without additional public assistance. Of those providers who were still open, enrollment was down by an average of $67 \%$, and more than $70 \%$ of respondents reported incurring substantial additional costs related to staff, cleaning supplies, and PPE (NAEYC, 2020). During the pandemic, many childcare teachers have experienced decreased wages, difficulty paying their bills, and anxiety about becoming ill (Bassok et al., 2020; Markowitz et al., 2020). Rates of self-reported symptoms of depression have spiked in both childcare teachers and public school pre-K teachers, despite the fact that public school teachers have fared better financially due to having higher salaries and remaining employed during the pandemic even when their schools were closed (Bassok et al., 2020). Public school teachers needed to pivot quickly from in-person to remote instruction and faced challenges regarding how to adapt 
lesson plans and keep young children's interest and attention during synchronous instruction (Bassok et al., 2020).

During the pandemic, childcare directors and school districts have faced many difficult challenges and choices: Can we survive financially with lower enrollment? Can we reopen safely during a pandemic? Can we provide meaningful remote instruction to children and support to parents during a shutdown? Can we maintain a focus on providing quality teacher-child interactions while navigating mask-wearing, social distancing, and worrying about our own health and safety? Early childhood teachers joined the ranks of those providing services to essential workers, facing fear of a serious contagious illness and adapting rapidly to new work demands in an unstable environment.

Meanwhile, mentors and coaches working with early childhood teachers were likewise challenged to continue to support their teachers and directors in the midst of challenges such as school closures, remote instruction, increased teacher stress levels, and inability to engage in face-to-face coaching and observations. In the following sections of this paper, we describe the results from surveys of early childhood teachers, administrators, and professional development (PD) specialists conducted in the spring and fall of 2020 through the Texas Early Childhood Professional Development System (TECPDS), as well as how a statewide PD program, Texas School Ready (TSR), adapted to the COVID pandemic.

We describe two studies which address the impact of COVID-19 on early childhood education. The first study used survey data collected from TECPDS users in April and November 2020 with the goal of explaining the broad impacts of the COVID pandemic on early childhood educators. The second study involved focus group and survey responses from TSR coaches with the goal of explaining how an existing statewide PD program for early childhood educators shifted activities amidst COVID to continue focusing on quality educator-child interactions. Our chief aim was to use these data to draw conclusions about how to ensure quality of early childhood education amidst pandemics, natural disasters, or other unexpected disruptions to early childhood programs.

\section{Study 1: Texas Early Childhood Professional Development System (TECPDS)}

TECPDS houses the education, training, and job experience records of more than 38,000 early childhood educators working in child care, Head Start, and public schools in the state. TECPDS is designed to help professionals understand early childhood education career pathways, learn about the state's core competencies for early childhood educators, and identify learning and educational opportunities that support skill development and career advancement. The platform also houses tools and resources, used by more than 700 training specialists, that are designed to improve access to and awareness of high-quality PD opportunities. Throughout the pandemic, the platform has been used as a communications and outreach tool to disseminate policy updates and resources that support safe reopening of schools, as well as professional training and child-centered activities to support responsive interactions and healthy development at home and school, in ways that meet CDC and local health agency guidelines. By surveying TECPDS users over time, we were provided a unique opportunity to examine how the COVID-19 pandemic affected professionals across diverse program contexts (i.e., child care, public school, Head Start) and professional roles.

\section{TECPDS Surveys: Methods}

In April 2020 and November 2020, we distributed a survey to users of TECPDS (i.e., early childhood program administrators/directors, practitioners/teachers, and trainers). The survey was focused on how COVID-19 impacted their work, and what specific supports they needed to do their jobs effectively. Both surveys were conducted using Qualtrics and distributed via email. Weekly reminder emails were sent for 2 weeks following the initial distribution. The April 2020 survey consisted of 23 items, and the November 2020 survey was expanded to 43 items. In November, we added items about educator stress (Maslach et al., 1986), and items from other published surveys on the impacts of COVID19 on early childhood education (Daro \& Gallagher, 2020; Groundwork Ohio, 2020; Pettit, 2020; Sonnier-Netto et al., 2020). Both surveys consisted of a mix of multiple-choice and open-ended questions and we obtained approval from the university's institutional review board to report on these data for research purposes.

In April 2020, 2135 early childhood educators responded to our survey. Of these respondents, 620 were administrators or directors of early childhood programs 182 were early childhood education trainers, and 1369 were teachers or practitioners (61 self-identified as more than one category, and 28 did not self-identify). In November 2020, 2382 early childhood educators responded to our survey; 783 were administrators or directors of early childhood programs, 164 were early childhood education trainers, and 1435 were teachers or practitioners (38 identified as more than one category, and 39 did not self-identify). $42 \%$ of the November survey respondents worked at public schools and $35 \%$ worked at child care centers. About $20 \%$ of respondents completed the survey at both time points. 


\section{TECPDS Survey: Results}

We were able to directly examine changes from April to November using the $20 \%$ of respondents who completed the survey at both timepoints (see Tables 1 and
2). In April, only $10.8 \%$ of administrators and directors reported that their centers were open with no changes, but by November, this number had increased to $35.6 \%$. Staffing levels similarly increased from April to November. Many teachers and practitioners reported that in April, they were still employed and being paid, but not working
Table 1 Survey response changes from April to November 2020: staffing and students

\begin{tabular}{|c|c|c|c|c|}
\hline & \multicolumn{2}{|l|}{ April } & \multicolumn{2}{|c|}{ November } \\
\hline & $\mathrm{N}$ & Valid \% & $\mathrm{N}$ & Valid \% \\
\hline \multicolumn{5}{|l|}{ Administrators/directors: status of center } \\
\hline Closed to everyone except essential personnel & 37 & 19 & 4 & 2.1 \\
\hline Open—limited capacity & 69 & 34.5 & 117 & 60.3 \\
\hline Open with no changes & 21 & 10.8 & 69 & 35.6 \\
\hline Permanently closed & 2 & 1 & 2 & 1 \\
\hline Temporarily closed & 66 & 33.8 & 2 & 1 \\
\hline Total (\# missing) & $196(1)$ & 100 & $195(1)$ & 100 \\
\hline \multicolumn{5}{|c|}{ Administrators/directors: number of staff hours worked per week } \\
\hline Between 0 and $50 \%$ of typical staffing levels & 118 & 68.7 & 51 & 27.7 \\
\hline Between 51 and $100 \%$ of typical staffing levels & 48 & 27.9 & 87 & 47.3 \\
\hline More than $100 \%$ of typical staffing levels & 6 & 3.5 & 46 & 25 \\
\hline Total (\# missing) & $196(24)$ & 100 & $195(11)$ & 100 \\
\hline \multicolumn{5}{|c|}{ Administrators/directors: have had to lay off or furlough staff? } \\
\hline \multicolumn{5}{|l|}{ No } \\
\hline Being paid full salaries & 64 & 36.8 & 102 & 57 \\
\hline Being allowed to use all accrued leave & 9 & 5.2 & 11 & 6.1 \\
\hline Being paid partial salaries & 29 & 16.7 & 16 & 8.9 \\
\hline Being provided with paid leave & 5 & 2.9 & 3 & 1.7 \\
\hline \multicolumn{5}{|l|}{ Yes } \\
\hline Furloughed & 23 & 6 & 13 & 7.2 \\
\hline Laid off & 44 & 25.3 & 34 & 19 \\
\hline Total (\# missing) & $196(22)$ & 100 & $195(16)$ & 100 \\
\hline \multicolumn{5}{|l|}{ Teachers/practitioners: changes to employment status } \\
\hline \multicolumn{5}{|l|}{ Laid off/furloughed } \\
\hline Will NOT return to the early childhood field & 1 & 0.4 & 1 & 0.4 \\
\hline Will return to work at the same facility/facilities & 11 & 4.7 & 3 & 1.3 \\
\hline \multicolumn{5}{|l|}{ Still employed } \\
\hline Decrease in work hours & 62 & 26.7 & 22 & 9.3 \\
\hline Increase in work hours & 1 & 0.4 & 1 & 0.4 \\
\hline Unpaid leave & 11 & 4.7 & 3 & 1.3 \\
\hline Paid leave & 83 & 35.8 & 5 & 2.1 \\
\hline Working full-time (no change) & 28 & 12.1 & 130 & 55.1 \\
\hline Voluntarily left job with plans to return to the field & 2 & 0.9 & 2 & 0.8 \\
\hline Total (\# missing) & $258(26)$ & 100.0 & $255(20)$ & 100.0 \\
\hline \multicolumn{5}{|c|}{ Administrators/directors: providing remote curriculum instruction/activities for children } \\
\hline No & 83 & 45.9 & 131 & 72.4 \\
\hline Yes & 98 & 54.1 & 50 & 27.6 \\
\hline Total (\# missing) & $196(15)$ & 100.0 & $195(14)$ & 100.0 \\
\hline \multicolumn{5}{|c|}{ Teachers/practitioners: are you in contact with your students at this time? } \\
\hline No & 20 & 13.9 & 12 & 5.3 \\
\hline Yes & 124 & 86.1 & 216 & 94.7 \\
\hline Total (\# missing) & $258(114)$ & 100.0 & $255(27)$ & 100.0 \\
\hline
\end{tabular}


Table 2 Survey response changes from April to November 2020: professional development

\begin{tabular}{|c|c|c|c|c|}
\hline & \multicolumn{2}{|l|}{ April } & \multicolumn{2}{|c|}{ November } \\
\hline & $\mathrm{N}$ & Valid \% & $\mathrm{N}$ & Valid \% \\
\hline \multicolumn{5}{|l|}{ Trainers/coaches: are you still providing training? } \\
\hline No & 21 & 53.8 & & \\
\hline Yes & 18 & 46.2 & & \\
\hline A little less than before COVID-1 & & & 6 & 18.2 \\
\hline A little more than before COVID-1 & & & 3 & 9.1 \\
\hline A lot less than before COVID-19 & & & 10 & 30.3 \\
\hline About the same as before COVID-19 & & & 10 & 30.3 \\
\hline Much more than before COVID-19 & & & 4 & 12.1 \\
\hline Total (\# missing) & $40(1)$ & 100.0 & $44(11)$ & 100.0 \\
\hline \multicolumn{5}{|l|}{ Trainers/coaches: using what method(s)? } \\
\hline Coaching & 3 & 17.6 & 5 & 16.1 \\
\hline Online courses/webninar training & 10 & 58.8 & 9 & 29 \\
\hline Both coaching and online courses/webinar training & 4 & 23.5 & 17 & 54.9 \\
\hline Total (\# missing) & $40(23)$ & 100 & $44(13)$ & 100 \\
\hline \multicolumn{5}{|c|}{ Administrators/directors: are you currently providing PD and/or meetings for staff? } \\
\hline No & 99 & 54.1 & 49 & 27.2 \\
\hline Yes & 84 & 45.9 & 131 & 72.8 \\
\hline Total (\# missing) & $196(13)$ & 100 & $195(15)$ & 100 \\
\hline
\end{tabular}

any hours $(35.8 \%)$ or still employed but working decreased hours $(26.7 \%)$. In November, these teachers and practitioners reported being still employed and working full time $(55.1 \%)$ or still employed and working increased hours (29.2\%). These trends within the teachers who responded to our survey at both time points are also reflected in the trends across all respondents, described below.

The survey results from April to November revealed several themes. First, enrollment and attendance numbers declined as a result of the pandemic. Second, teachers faced new technology demands as their teaching and PD moved online. Third, as early childhood programs reopened, educators faced new challenges to keep up with cleaning, documentation related to COVID-19 policies, and teaching. As a result of these changes, early childhood educators reported increased work-related stress. Amidst their own personal stressors, these educators expressed concerns for children and families and reported going above and beyond to help meet children's needs. Finally, some educators highlighted positive changes in the workplace as a result of the COVID19 pandemic.

\section{Decline in Enrollment and Attendance Numbers}

In November 2020, the majority of early childhood administrators and directors who responded to our survey $(79 \%)$ indicated that one of the challenges they faced was that families were keeping their children at home as a result of the pandemic, and 70\% reported that the COVID-19 pandemic caused their center financial stress. In both April and
November, when asked what kind of support they needed, some administrators and directors emphasized a need for financial support and ways to increase enrollment numbers. For example, in April, one respondent reported that they needed financial support because "We have lost $55 \%$ of our enrollment out of fear of the virus. Those parents are not paying tuition for the entire month of April." Also in April, many early childhood programs were focused on children of essential workers, so one respondent reported that they needed "assistance for advertisement for first responders and essential workers to inform them that quality child care is available to their families." By November, we saw more requests for ways to increase in-person enrollment, as evidenced by responses like these: "We need help so we can motivate parents to bring their children. We used to have 144 students and our attendance today is 29 students," and, "I need parents to register their kids. My staff is ready to work and so am I."

\section{New Technology Demands}

Because of social-distancing restrictions, early childhood educators had to explore new methods of teaching and PD using technology. In April, 58\% of administrators and directors who responded to our survey said that their centers were delivering remote instruction to children, and $66 \%$ of trainers who responded to our survey reported moving their training online. These trainers reported that their greatest challenges with training were technical difficulties and keeping participants engaged. For example, one trainer reported "I 
think a big challenge is just learning how to navigate Zoom and to change the format of my sessions. I like small group work, discussion, and hands-on learning, and those are very difficult with online teaching." Early childhood teachers faced similar challenges moving their teaching online. In April, many teachers who responded to our survey requested help planning activities for remote learning, particularly for younger children, low-income families, and Spanish-speaking children: "Guide to carry out an on-line session with students so little;" "Ideas of things the children can do at home with or without a computer;" "Information on sites that provide games in Spanish for my PreK students that are free."

These difficulties with translating early childhood education to a remote format persisted into the fall; $35 \%$ of teachers who completed our November survey indicated that training in virtual learning was one of their top three PD needs. In addition, $21 \%$ of our November survey respondents mentioned that they were responsible for both face-to-face and virtual instruction. With this added workload, some teachers reported that they did not feel as though they were able to support their students fully. One respondent said, "Teaching remotely often feels like I am learning to teach all over again. Ideas on how I can improve would be helpful. I constantly worry whether or not I am doing things right in order for my students to be successful." Another said, "Teaching half of my class online and the other half in class has been a HUGE adjustment. I am exhausted mentally and physically by the double work load. I do not feel like either class is getting my best and that breaks my heart."

\section{Increased Workload}

With time, COVID-19 health guidelines have become clearer, including wearing masks, social-distancing, and disinfecting surfaces. Establishing protocols for keeping children and staff safe has allowed early childhood centers to re-open, but has also placed an added burden on staff to enforce the protocols. For example, in April, only 15\% of administrators who responded to our survey reported that they expected their staff to follow health and safety protocols at work, but in November, $52 \%$ stated this as an expectation for their staff. $43 \%$ of our November survey respondents also highlighted the new health and safety protocols as the main change to their job responsibilities since the start of the pandemic: "I have to make sure students are regularly washing their hands, sanitize everything the students touch after every use. I have to be a mask police, keeping-distance police. Make sure the students are not sharing anything etc." Some of these added responsibilities have increased the number of hours early childhood educators are working: "A lot of new procedures have been put in place. Cleaning extra or staying longer to disinfect. Because not all workers returned after we opened back up, those of us who did return have been working longer hours when needed." For teachers that are responsible for following these health protocols, teaching children face-to-face, and teaching children remotely, the workload may be even heavier: "My day starts earlier in order for students to have breakfast in our classrooms and we leave later in order to meet with online students. We have to clean our rooms frequently throughout the day as well."

This increased workload is reflected in other survey questions as well. In April, when asked what support they needed, the most common response our survey respondents gave was none ( $29 \%$ of respondents). These educators said things like, "My campus and district are doing a great job of supporting me right now," and "I'm handling things 1 day at a time. The district is providing wonderful support for whatever we need." By November, the most common response to this question was that these educators needed more time or a reduced workload (20\% of respondents). Some of these educators mentioned that their workload increased because they were expected to teach students in-person and virtually: "I need to not do 3 different jobs at one time. I am taping videos, zooming with students, and teaching students in class." Others also mentioned that the new health and safety protocols require more paperwork, which adds to their workload: "COVID has added so much documentation to our teams and teachers, there is not enough time in the day to both be with students and document everything that is being asked."

\section{Increased Work-Related Stress}

In November, we asked survey respondents how their jobrelated feelings and mental or emotional health changed since the start of the COVID-19 pandemic. A majority of respondents reported that they have more frequent feelings of job-related stress now than before the COVID-19 crisis, including feelings of emotional drain $(\sim 72 \%)$, fatigue $(\sim 60 \%)$, and frustration $(\sim 57 \%)$. A relatively lower percentage of educators reported that they worried more often that their job was hardening them emotionally $(\sim 36 \%)$ or that they felt more often that working with people directly put much stress on them ( 34\%). In addition, about $67 \%$ of respondents indicated that they felt nervous, anxious, or worried more often and about $48 \%$ felt down, depressed or hopeless more often than before the COVID-19 crisis. We also asked respondents whether the pandemic has caused them personal financial stress. $49 \%$ of respondents agreed that COVID-19 has caused them personal financial stress. $65 \%$ of early childhood educators also reported that the pandemic has made it difficult to balance their different work responsibilities. 


\section{Concerns for Children and Families}

The educators who responded to our survey also expressed concern about children and families. In November, 33\% responded that they were concerned about the physical health and safety of their families, $23 \%$ were concerned about the financial burden of families, and $18 \%$ were concerned about the mental health of families. When asked whether the pandemic was having a positive or negative impact on child-adult interactions, $78 \%$ of early childhood educators thought that the pandemic had a negative impact on child development. Some of the reasons given were that masks prevented children from seeing adults' facial expressions, adults cannot give children hugs because of COVID19 , virtual communication is not the same as in-person interaction, and adult stress may impact interactions with children.

When asked how they were supporting the families they serve, the most common response in both April (41\%) and November (45\%) was keeping open communication with parents. More specifically, many educators have opened themselves up to communicating with parents outside of normal work/school hours and trying to provide them with support and resources. For example, "I speak to them on the phone frequently. I try to be positive and encourage them to keep moving forward. I also share resources with them that they may not be aware of;" "I have encouraged parents to reach out with any concerns they may have, and I will do my best to help them, or provide them with information of someone who can;" "Passing on the information I receive regarding health and safety, financial assistance, and offering myself as a person they can talk to or get items they need (food, clothes, cleaning supplies)."

In April, many educators said they were supporting families by providing remote learning (36\%) and remaining open for in-person childcare (20\%). By November, more respondents reported that they were supporting families by providing supplies or resources $(25 \%)$, rather than providing remote learning $(11 \%)$ or remaining open for in-person childcare (7\%). For example, "gift cards, free food, case management, and Christmas gifts for the children," and "resources that are free to them such as internet service, devices, food bank, speech services, and other items needed to provide education and basic needs at home." This suggests that in November, early childhood centers were taking on not only the role of caring for and educating children, but also helping parents meet some of their basic needs at home.

\section{Positive Changes in the Workplace}

Although the workload seems to be a major concern for many early childhood educators, some also viewed new health guidelines and the ability to teach students in their homes as positive outcomes of the pandemic. For example, $11 \%$ of our survey respondents mentioned that fewer children have gotten sick because of the enhanced health and safety procedures: "We have taken a new stance on what and how we clean our facilities. I have noticed a decrease in the typical childhood illnesses such as hand/foot/mouth, common cold, and pink eye;" "First time in 20 years working with young children that I have not gotten sick at the start of the school year. It must be because of the mask." Some (7\%) also mentioned that providing remote instruction meant that they could form more personal connections with families: "I have gotten to know my students and their families with greater depth because I see them with their pets, mothers, fathers, brothers, sisters and grandparents. Also, when they are celebrating something, they can really bring you into their home to show you and the rest of the class how they observe a holiday or tradition." Being forced to develop new technology skills was also something that some (13\%) of our November survey respondents highlighted as a positive outcome of the pandemic. These respondents said things like: "I have so much more technical knowledge and it's knowledge I can use after this is over," and, "I have become highly skilled with on line instruction and the creation of lessons both in English and in Spanish. I am able to use computer programs with ease and enjoy creating fun and engaging online activities for my students!".

\section{Study 2: Response of a Scaled Statewide Preschool Program}

The goal of our second study was to explain how an existing statewide PD program for early childhood educators adapted during the COVID-19 pandemic in order to provide practical recommendations for other PD programs. The Texas School Ready (TSR) program began in 2003 and was known nationally as the Texas Early Education Model (TEEM). The Texas state legislature funded this program to improve the quality of early education opportunities for preschoolers considered at risk due to factors such as poverty. Early demonstration projects as well as scale-up research studies demonstrated significant impacts of TSR for enhancing the quality of teacher behaviors and children's school readiness outcomes (Landry et al., 2006, 2009, 2011). As TSR expanded from 11 initial communities to 20 current communities serving 1000 to 1500 preschool teachers annually, it continued to encourage sharing resources among three groups of childcare programs that serve at-risk preschool-age children: public pre-kindergarten, Head Start grantees, and childcare centers participating in the Child Care and Development Fund subsidy program (Crawford et al., 2020). The core components of the TSR program include: (a) teacher PD courses, (b) individualized coaching for teachers, (c) 
progress monitoring assessment tools that teachers administer to guide instruction, and (d) provision of researchbased, state-approved curricula. The PD and service delivery is managed by a team of university-based early childhood education experts (see Crawford et al., 2020).

The TSR program was well positioned to shift quality improvement efforts to online delivery at the start of the 2020 pandemic because we had executed a long-term plan to build the capacity and infrastructure for delivery of online services that was envisioned almost a decade earlier. In 2012-13, in partnership with the Texas Education Agency, the Children's Learning Institute (CLI) began planning and developing a cost-effective, online delivery system for TSR called CLI Engage. The CLI Engage system was designed to disseminate TSR's tools-online courses, remote coaching, online progress-monitoring measures, and digital curricula-across the state at low cost. We created a strategy to develop, assess, and deploy these components over time. This process of moving a quality improvement program from face-to-face to online required multiple years and considerable investments to align components within the online system (see Crawford et al., 2017). For example, to deliver coaching remotely we first created and validated online observation tools for coaches to monitor teachers' implementation of evidence-based practices and set goals for improvement (Crawford et al., 2013). During the 2014-2015 school year, we conducted a large-scale pilot of the TSR tools and resources on the CLI Engage platform with 2450 teachers to refine the system for statewide launch in Fall 2015. At this same time, we began expanding and validating the student progress monitoring measures (e.g., Montroy et al., 2020; Zucker et al., 2016). Other components such as the launch of a comprehensive digital curriculum occurred in later phases (Children's Learning Institute, 2020). Because the TSR program had been gradually developing an online infrastructure, this program continued to deliver services during the COVID-19 pandemic. Nonetheless, this program faced challenges and adapted their approaches during the pandemic, which we describe in the following sections.

\section{TSR Focus Group \& Survey Methods}

We conducted a virtual focus group with six program managers and their two supervisors who manage delivery of the program six regional service areas in Texas. Program managers provide training, technical assistance and supervision to all TSR coaches and staff; therefore, these staff observed a variety of coach-teacher interactions and provided feedback to ensure fidelity to the model and to problem solve amidst COVID. TSR coaches provided $4 \mathrm{~h}$ of coaching per month to their assigned teachers enrolled in the first year of the program. The hours of coaching were reduced for teachers enrolled in the second year of TSR to $2 \mathrm{~h}$ per month and less frequent maintenance sessions for teachers in the third year of the program. We surveyed the same six program managers and the 65 coaches they supervised who deliver the program in preschool classrooms for children ages $3-4$. We had a $98.33 \%$ survey response rate $(n=59$ coaches). Key questions asked were, "What challenges are you having with coaching this year?;" "For teachers who are delivering any faceto-face instruction, describe how they have modified their instruction to meet COVID social distancing restrictions or other changes related to the pandemic;" and "For teachers who are teaching virtually or in hybrid models, describe how they are delivering this instruction." Themes were identified by analyzing the transcript of the focus group "chat" and open-ended survey questions. We obtained approval from the university's institutional review board to report on these data for research purposes.

\section{TSR Focus Group \& Survey Results}

In the 2020-21 school year that was impacted by COVID, TSR served over 1200 preschool teachers monthly by offering online delivery of all components. The core TSR components were modified such that: (a) the online PD courses were facilitated via videoconference, rather than previous blended learning approaches that combined online courses with in-person activities; (b) remote or face-to-face coaching choices were given, depending on local COVID requirements for coaches visiting classrooms; (c) online progress monitoring assessments were modified for remote delivery, if teachers were providing virtual instruction; and (d) a new state-approved, digital curricula was provided. Coaches reported that $71.90 \%$ of TSR teachers served provided exclusively face-to-face instruction, $9.06 \%$ exclusively virtual, and $19.04 \%$ provided hybrid models. The vast majority of teachers/schools requested remote coaching $(91.14 \%$ remote; $8.86 \%$ face-to-face coaching). For TSR teachers using virtual or hybrid models, each day they delivered an average of 2.00 synchronous sessions (SD 1.08, Range 1-4) and 2.09 asynchronous assignments (SD 0.99, Range 0-4). For synchronous sessions, most teachers used a videoconference platform (e.g., Zoom https://zoom.us, Microsoft Teams https://teams.microsoft.com/) that typically featured the "circle time" activities of a read aloud and introduction of new concepts. Coaches reported that a small number of teachers who did not have videoconference technologies available sent recorded videos and resources (e.g., YouTube https:// www.youtube.com, CIRCLE Activity Collection https:// cliengage.org/public/tools/materials/) instead of a synchronous lesson. Asynchronous assignments were shared with families typically via Google classroom (https://classroom. google.com) or other online services (e.g., SeeSaw https:// 
web.seesaw.me, Clever https://clever.com). The qualitative focus group and survey data revealed four themes for TSR coaches: Managing Stress, Encouragement \& Flexibility, Improving Remote Competencies, and Concerns about Developmentally Appropriate Practice.

\section{Managing Stress}

This theme captured participants' intense feelings of stress in responding to the changing COVID situation that resulted in staffing shortages at many classrooms/schools, students and teachers exposed to or contracting COVID, and low or inconsistent student enrollment in preschools. Program managers described teachers as exhibiting higher stress: "The pandemic has put a strain on the quality of adult-child interactions. Adults are faced with so many stressors with much more on their plates than normal. They do not have the same level of energy to interact positively with the children in their care." These quotes from coach surveys illustrate teachers' typical state: "The pressure. Our teachers are under so much stress already and we are asking them to do more. They are feeling tired and stressed" and "Teachers are being quarantined for 14 days or more due to [COVID] exposure at the center." Multiple coaches noted: "Teachers are overwhelmed when doing virtual and F2F learning" because this includes teaching in person as well as, "uploading homework and videos for parents, following up with parents who don't respond, and all of the assessments and paperwork like [parent] communication logs." Regarding PD assignments, a coach explained, "Most of our teachers are keeping up, but we have some that are really struggling." Several coaches explained that it was very challenging finding time to schedule the remote coaching video reflection/goal setting meetings because these meetings required other staff to supervise their students: "Keeping meetings with teachers with reduced staffing has been challenging." This coach and others reported scheduling meetings during teachers' lunch break or when they were off duty/evenings. Some coaches noted that staffing shortages were more prominent at rural sites.

The changing student enrollment situation was another common source of teacher stress: "Class attendance is different every day. Some days the teachers will have 8-14 and some days only 4." Some early childhood programs had flexible options for elementary students to attend, as needed, which generated income but caused stress: "Schools close and then our centers are flooded with school age children until the [elementary] schools open back up again. We are doing the best we can it just seems to be a very chaotic year for so many of our centers... [it] truly seems to be a revolving door." Finally, another stressor was teachers' job security: "Teachers are more concerned with having a job than providing quality care to children. They don't have energy to focus on quality lesson plans, activities, and interactions." Although managers and coaches observed significant stressors, most included positive comments that they believed teachers were still engaged in PD and learning while managing uncertainties and stressors of COVID. For example, a coach concluded "Many of my teachers are self-motivated and enjoy learning, growing, collaborating, etc. They are making the best of the situation, doing what's best for their students."

\section{Encouragement \& Flexibility}

This theme reflects the fact that, although coaches recognized the teachers they coached were stressed, fatigued, or "just trying to survive," coaches viewed their role as a unique opportunity to provide encouragement and support during COVID. One coach explained, "I feel like I am a great resource to the teachers for stress management and ideas on how to incorporate the new ways of teaching." Another coach described how she supports teachers: "I make sure I communicate with my teachers each week via email or text. I give them words of encouragement and tell them to call me if they need to talk. It's hard for these teachers to decide to go to work each day and make $\$ 7.50$ an hour when your life is at stake... that's the truth of the matter." She went on to explain how she views showing genuine care and concern in tough times as a sign of character. Another coach explained that to be as supportive as possible, she reminded herself, "Most days I really don't know what all of my teachers have to deal with." Several respondents viewed their role as "coaching teachers through burnout and overload."

A theme connected to encouraging teachers was demonstrating flexibility around PD requirements. One coached summarized this idea by saying, "I've explained to teachers that this year we are being highly flexible, but we will still teach them best practices...I've had great coaching conversations with teachers and feel connected to them even if it's over video and zoom." Coaches' flexibility was demonstrated by shifting coaching goals if/when teachers were learning to deliver virtual instruction: "I am being very flexible and conforming my coaching to where they tell me they need help based on their struggles or shifting teaching to virtual." Likewise, many coaches reported "Our teachers have been very flexible and cooperative in adjusting to the remote from the face to face [coaching]." Coaches demonstrated awareness that this PD was an enhancement and that "when in dire straits, the "extras' are the first to go." Yet, multiple coaches and program managers noted that the TSR program offered support that helped schools get through the pandemic. For example, one coach/coordinator explained "Administrators are excited about being able to continue/ start with TSR. This can bring some sort of normalcy in the classroom as we get back to teaching." 


\section{Improving Remote Competencies}

This theme encapsulates the coaches' ability to make improvements in delivering PD remotely and to use creative approaches to building relationships with teachers remotely. In the beginning of the pandemic, it was not easy for teachers and coaches who had been doing face-to-face coaching to shift to remote coaching because: (a) they had to learn to give feedback without real-time "side-by side coaching and co-teaching;" (b) they needed to complete the remote coaching cycle that requires time for the teacher to upload the video and the coach to edit the video; and (c) they were faced with teachers' technical issues, especially "helping teachers who are not tech-savvy." Program managers observed that it took time, training and technical assistance for coaches to develop competencies to successfully coach in a remote modality. For example, managers noted: “They can't build relationships the same way, but coaches are coming up with new and innovative ways to build and foster those interactions" or coaches are "using the [online] CIRCLE Activity Collection videos" instead of modeling things like effective classroom management approaches in-person.

Many coaches articulated increasing self-efficacy for delivering remote coaching and noticed benefits of this approach relative to face-to-face coaching. One coach said, "I feel like the videos are a huge success. I really like being able to slow down and provide more detailed feedback. Sometimes that's hard 'in the moment' when the teacher has a class full of kids. And I believe the feedback videos are really helping the teachers see and reflect more on their teaching." This theme was articulated by other coaches who said, "the feedback videos are really helping the teachers see and reflect more on their teaching" and "we have made huge strides...I feel like the content I am coaching on is better content." But this was not easy for many coaches who noted their own challenges with changing habits, "I'm such a face-to-face coach that my mind and heart, honestly, are my biggest challenges. I'm adapting and even though it is a challenge...I can and am making this a successful school year for my teachers. That's my job."

In terms of delivering courses remotely (rather than the pre-COVID blended learning approach) coaches explained "It has been helpful to speak with other coaches to bounce off ideas on how to overcome some barriers and figure out what is working and what is not. In our community we partnered up as coaches to facilitate virtual eCIRCLE courses and we alternate between one of us presenting the information and the other handling WebEx issues, chat box, breakout rooms, etc." TSR staff also spent time during PD videoconference sessions highlighting the "silver linings" they observed amidst COVID. For example, teachers who are "lucky enough to have students in their classrooms are trying to be more responsive with their interactions with them.
We observe some great language support strategies when teachers only have a few students back face-to-face." Many coaches reported that having a virtual community through TSR PD helped teachers feel socially connected. Attendance at eCIRCLE courses was also easier for many teachers (especially rural sites) since they did not have to travel to the community centers for the courses.

\section{Concerns about Developmentally Appropriate Practice (DAP)}

A minor theme that was only noted by about $10 \%$ of coaches was concerns that some COVID regulations resulted in situations that were not DAP for young children. Many coaches explained that centers had reduced the number of materials in the classroom and were "only using materials that withstand constant sanitizing." But in some centers with limited resources the result was "very limited materials are out in the classroom" and there were limited materials for literacy such that "there [were] no writing materials or books in centers" because these could not be sanitized between multiple center rotations. Although most centers allowed masked students to work together at a safe distance or with an assigned partner (for contact tracing), some classrooms restricted students' physical movement such that "there are no interactions amongst students." Coaches described these situations where "Students have to be at their desks all day. At center time, they choose an activity to work on alone at their desk" or that "students must sit in their area (cubicle) alone the whole time." In these situations, coaches shared lists of ways to promote safe social interactions and offer more appropriate materials so that teachers could consider how to promote DAP amidst their local COVID restrictions.

\section{Discussion}

The TECPDS registry allowed for a mass deployment of surveys to early childhood professionals across Texas. A well-developed state registry such as TECPDS proved to be a critical platform that allowed us to gauge how the Texas early childhood workforce is faring during the global pandemic. The data collected highlighted how statewide efforts to reopen early childhood programs and continue quality improvement initiatives have not been without challenges. These challenges, as indicated by survey responses from focus groups with early childhood professionals, have generally corroborated other findings (e.g., Markowitz et al, 2020; NAEYC, 2020; Zero to Three, 2020) that spanned a variety of issues such as declining enrollment, increased technology demands (e.g., delivering remote instruction or training), increased workloads (e.g., implementing new safety protocols), increased stress levels, and new expectations 
(e.g., helping families access additional resources). Based on these challenges, two key implications emerged: (1) balancing expectations and capacity and (2) PD opportunities around key focal areas.

\section{Balancing Work Expectations and Capacity}

The many challenges noted by early childhood professionals in the current report suggest the importance of weighing professional requirements against early childhood professionals' capacity or "bandwidth". A recent study by Sokal et al. (2020) interprets the stress and burnout of teachers during the COVID-19 pandemic from the perspective of the job demands-resources model (Bakker \& Demerouti, 2007). In this model, stress is the result of work demands (e.g., remote teaching, in-person teaching, cleaning, paperwork, PD) that exceed the available resources (e.g., support from administrators, classroom aides, parents, etc.). As one of our survey respondents put it, many early childhood educators are "doing what I can, but I got no magic wand." Over time, prolonged stress at work can lead to educator burnout. Importantly, Sokal et al. point out that over time, resources can be depleted, which may exacerbate stress. This may be the case for educators in Texas, as the results of our survey indicated that while in April, many educators felt that they did not need any additional support, by November we saw many requests for support that included more time in the day or a reduced workload. Thus, the increased demands placed on early childhood professionals have likely contributed to the elevated feelings of emotional drain, fatigue, and frustration reported in our survey.

Despite these demands, there have been ongoing expectations for early childhood professionals to participate in ongoing PD opportunities during the pandemic. Findings from the current report remind us to prioritize early childhood professionals' physiological and safety needs (i.e., Maslow's Hierarchy; Lockee, 2020; Maslow, 1962) when considering the expectations placed on early childhood professionals. That is, many of the supplemental professional expectations (e.g., participation in PD) placed on early childhood educators may not be appropriate if their basic needs (e.g., safety, job security, health) are not fully met or if they do not have the necessary resources to meet all of their work demands. Thus, adjusting expectations and supports for early childhood professionals seem to be especially important when navigating the many transitions that have emerged during the pandemic.

\section{Professional Development (PD) Opportunities Around Key Focal Areas}

Feedback across the surveys and focus groups also indicated the importance of PD that was highly responsive to the current needs of early childhood professionals. Increasingly, this need has been focused on remote delivery of instruction or training. In our own state-funded work, we have re-designed and developed new trainings to help early childhood professionals learn how to adapt instruction, coaching, and training for remote delivery. For example, we have delivered several trainings focused on utilizing technology that could help foster engagement among participants (e.g., use of Kahoot!, Zoom breakout rooms, chat functionalities) and tips for improving remote delivery (e.g., sending electronic copies of presentation materials before an online training; incorporating frequent breaks to promote engagement; use of chat boxes to encourage active listening and learning). More than ever, it is important to adapt and create content for PD that prioritizes early childhood professionals' immediate needs.

In Table 3, we provide practical recommendations for adapting and/or creating PD opportunities. These recommendations are organized by content (the "what"), process (the "how"), and structure (the "when," "where," "who," and "for how long"). For example, we created new content on how early childhood trainers could modify and adapt trainings for virtual delivery. We also examined and iteratively modified processes so that program-level expectations were aligned with participants' capacity (e.g., levels of engagement, abilities to participate). This resulted in a significant expansion of our digital resource collections, which allowed early childhood professionals to freely access resources and participate in more self-paced online trainings. Finally, significant structural changes consisted of the shift to exclusively remote service delivery. For some, successful implementation of remote delivery may require openness to change, willingness to experiment with new approaches, and flexible routines.

\section{Limitations \& Future Directions}

The current study highlights the difficulties and experiences of early childhood professionals working in a variety of settings. It is important to note that experiences shared by professionals are likely influenced by the program setting in which they are working. For example, rates of job loss varied from public programs to private child care settings, and educators who did not experience job loss were more likely to face the challenges of virtual instruction (Bassok et al., 2020; Tarrant \& Nagasawa, 2020). Moreover, the findings from our research reflect the state of early childhood professionals in Texas, but the impact of the COVID-19 pandemic may be different in other states because stay-at-home orders and restrictions on child care and education differed across states (Elessar, 2020). These findings are also limited by the time and resource constraints of surveying early childhood professionals during the COVID-19 pandemic. In March and 
Table 3 Practical recommendations for professional development (PD)

\begin{tabular}{|c|c|c|}
\hline $\begin{array}{l}\text { Professional devel- } \\
\text { opment compo- } \\
\text { nents }\end{array}$ & Strategies & Examples \\
\hline Content & $\begin{array}{l}\text { Adapt content to be delivered } \\
\text { Frontload specific topics } \\
\text { Develop new content } \\
\text { Train on remote delivery strategies }\end{array}$ & $\begin{array}{l}\text { Identify parts of content that can be readily supplemented with fam- } \\
\text { ily engagement components } \\
\text { Create content on supporting adult social emotional wellbeing (e.g., } \\
\text { managing adult stress) that is delivered early on to early child- } \\
\text { hood professionals } \\
\text { Create family engagement kits that could be used to support at- } \\
\text { home learning } \\
\text { Use online platforms like Kahoot! or Zoom features (e.g., breakout } \\
\text { rooms, annotation feature) to engage participants during trainings }\end{array}$ \\
\hline Process & $\begin{array}{l}\text { Shift to resources that are readily available or self- } \\
\text { paced } \\
\text { Use digital facilitation strategies } \\
\text { Adopt strategies that enhance supportive coaching } \\
\text { presence for practitioners }\end{array}$ & $\begin{array}{l}\text { Use or assign virtually facilitated or self-paced courses instead of } \\
\text { in-person trainings } \\
\text { Share video recordings of classroom practices or photographs of } \\
\text { classroom environments } \\
\text { Use friendly texts to check in with professionals or provide informal } \\
\text { opportunities for professionals to share feelings and challenging } \\
\text { experiences during coaching sessions }\end{array}$ \\
\hline Structure & $\begin{array}{l}\text { Utilize remote training and coaching delivery models } \\
\text { Vary online learning formats } \\
\text { Incorporate flexible routines }\end{array}$ & $\begin{array}{l}\text { Adopt synchronous and asynchronous coaching formats that can be } \\
\text { delivered via webcam } \\
\text { Provide individualized coaching sessions (e.g., 1:1 coach-profes- } \\
\text { sional sessions), professional learning communities (e.g., small } \\
\text { groups of professionals), webinars (e.g., larger groups of profes- } \\
\text { sionals) } \\
\text { Offer "office hours" during which professionals can informally } \\
\text { check in with coaches }\end{array}$ \\
\hline
\end{tabular}

April, there was an urgency to understand how the COVID19 pandemic was impacting early childhood professionals and how professional development programs could adapt to meet educator needs. If not for this urgency, we would have taken more time to develop and pilot our survey items before distributing them to TECPDS users. Additionally, TSR was an established professional development program when the COVID-19 pandemic began. The challenges associated with remote-delivery of professional development programs may be different for newer programs.

The results of the research described here only capture the impact of the COVID-19 pandemic on early childhood educators during 2020. Future research should focus on longterm consequences, such as educator stress over time and in different communities. Future research should also consider the effectiveness of remote coaching and instruction for early childhood education. In conclusion, demands placed on early childhood professionals warrant greater sensitivity to the unique challenges that have emerged during this crisis.

\section{References}

Bakker, A. B., \& Demerouti, E. (2007). The job demands-resources model: State of the art. Journal of Managerial Psychology, 22, 309-328. https://doi.org/10.1108/02683940710733115
Bassok, D., Michie, M., Cubides-Mateus, D. M., Doromal, J. B., \& Kiscaden, S. (2020). The divergent experiences of early educators in schools and child care centers during COVID-19: Findings from Virginia. Retrieved May 27, 2021, from https://files.elfsight. com/storage/022b8cb9-839c-4bc2-992e-cefccb8e877e/710c4e384f63-41d0-b6d8-a93d766a094c.pdf

Child Care Aware of America (2019). The U.S. and the high price of child care: An examination of a broken system. Retrieved May 27, 2021, from https://info.childcareaware.org/hubfs/2019\%20Price\% 20of\%20Care\%20State\%20Sheets/Final-TheUSandtheHighPrice ofChildCare-AnExaminationofaBrokenSystem.pdf

Children's Learning Institute. (2020). CIRCLE Pre-K curriculum. Children's Learning Institute.

Crawford, A. Varghese, C. \& Monsegue-Bailey, P. (2020) The implementation and scaling of an early education program. Journal of Applied Research on Children: Informing Policy for Children at Risk, 11(1). Retrieved May 27, 2021, from https://digitalcom mons.library.tmc.edu/childrenatrisk/vol11/iss 1/4

Crawford, A. D., Zucker, T. A., Williams, J. M., Bhavsar, V., \& Landry, S. H. (2013). Initial validation of the prekindergarten classroom observation tool and goal setting system for data-based coaching. School Psychology Quarterly, 28(4), 277. https://doi.org/10.1037/ spq0000033

Crawford, A., Zucker, T., Van Horne, B., \& Landry, S. (2017). Integrating professional development content and formative assessment with the coaching process: The Texas school ready model. Theory into Practice, 56(1), 56-65. https://doi.org/10.1080/00405 841.2016.1241945

Daro, A. \& Gallagher, K. (2020). The Nebraska COVID-19 early care and education provider survey II. Retrieved May 27, 2021, from https://issuu.com/buffettearlychildhoodinstitute/docs/provider_ survey_2_080420_final 
Elessar, A. (2020). This is where each state is during its phased reopening. CNN.

Groundwork Ohio. (2020). Ohio childcare provider COVID-19 survey data. Retrieved May 27, 2021, from https://legacy.earlysuccess. org/sites/default/files/GroundworkChildCareSurveyDataReport. pdf

Landry, S. H., Anthony, J. L., Swank, P. R., \& Monseque-Bailey, P. (2009). Effectiveness of comprehensive professional development for teachers of at-risk preschoolers. Journal of Educational Psychology, 101(2), 448. https://doi.org/10.1037/a0013842

Landry, S. H., Swank, P. R., Anthony, J. L., \& Assel, M. A. (2011). An experimental study evaluating professional development activities within a state funded pre-kindergarten program. Reading and Writing, 24(8), 971-1010. https://doi.org/10.1007/ s11145-010-9243-1

Landry, S. H., Swank, P. R., Smith, K. E., Assel, M. A., \& Gunnewig, S. B. (2006). Enhancing early literacy skills for preschool children: Bringing a professional development model to scale. Journal of Learning Disabilities, 39(4), 306-324. https://doi.org/10. 1177/00222194060390040501

Lockee, B. B. (2020). Shifting digital, shifting context: (re)Considering teacher professional development for online and blended learning in the COVID-19 era. Education Technology Research and Development. https://doi.org/10.1007/s11423-020-09836-8

Markowitz, A.J., Bassok, D., Smith, A., Kiscaden, S. (2020). ChildCare teachers' experiences with COVID-19: Findings from the study of education in Louisiana. Report No. 2. Retrieved May 27, 2021, from https://files.elfsight.com/storage/022b8cb9-839c-4bc2-992ecefccb8e877e/a9f96482-73b5-4daa-afbd-dcec0741670b.pdf

Maslach, C., Jackson, S. E., \& Schwab, R. L. (1986). Educators Survey of the Maslach Burnout Inventory. Consulting Psychologists Press.

Maslow, A. (1962). Toward a psychology of being. D Van Nostrand. https://doi.org/10.1037/10793-000

Montroy, J. J., Zucker, T. A., Assel, M. M., Landry, S. H., Anthony, J. L., Williams, J. M., et al. (2020). The Texas kindergarten entry assessment: Development, psychometrics, and scale-up of a comprehensive screener. Early Education and Development. https:// doi.org/10.1080/10409289.2020.1726700

National Association for the Education of Young Children (2020). Holding on until help comes: A survey reveals child care's fight to survive. Retrieved May 27, 2021, from https://www.naeyc.org/ sites/default/files/globally-shared/downloads/PDFs/our-work/ public-policy-advocacy/holding_on_until_help_comes.survey_ analysis_july_2020.pdf

Pettit, L. (2020). Survey results: How COVID-19 is impacting child care providers. Retrieved May 27, 2021, from https://www.lena. org/covid-child-care-survey-2/

Sokal, L. J., Trudel, L. G. E., \& Babb, J. C. (2020). Supporting teachers in times of change: The job demands-resources model and teacher burnout during the COVID-19 pandemic. International Journal of Contemporary Education, 3(2), 67-74. https://doi.org/10.11114/ ijce.v3i2.4931

Sonnier-Netto, L., Cope, H., Falgoust, T., Oakey-Frost, R., \& Lewis, R. (2020). The impact of COVID-19 on Louisiana child care providers. Retrieved May 27, 2021, from https://0cd902dd-9de1-4dae8781-4a355ebda8df.filesusr.com/ugd/43cca3_82059779549845e e93dcdca7da8c65a8.pdf

Tarrant, K., \& Nagasawa, M. (2020). New York early care and education survey: Understanding the impact of COVID-19 on New York early childhood system. Retrieved May 27, 2021, from https:// earlychildhoodny.org/research/docs/NY\%20ECE\%20Workforce\% 20COVID\%20Survey\%20Full\%20Report.pdf

U.S. Chamber of Commerce Foundation, Center for Education and Workforce (2020). Childcare: An essential industry for economic recovery. Retrieved May 27, 2021, from https://www.uschamberf oundation.org/sites/default/files/media-uploads/EarlyEd_Minis_ Report3_090320.pdf

Workman, S., \& Jessen-Howard, S. (2020). The true cost of providing safe child care during the coronavirus pandemic. Center for American Progress.

Zero to Three (2020). How COVID-19 is impacting child care providers. Retrieved May 27, 2021, from https://www.zerotothree.org/ resources/3398-how-covid-19-is-impacting-child-care-providers

Zucker, T. A., Williams, J. M., Bell, E. R., Assel, M. A., Landry, S. H., Monsegue-Bailey, P., et al. (2016). Validation of a brief, screening measure of low-income pre-kindergarteners' science and engineering knowledge. Early Childhood Research Quarterly, 36, 345-357. https://doi.org/10.1016/j.ecresq.2015.12.018

Publisher's Note Springer Nature remains neutral with regard to jurisdictional claims in published maps and institutional affiliations. 